\title{
An IMISCOE effect? The role of a network of excellence in developing European migration research in the twenty-first century
}

Nathan Levy

Correspondence: levy@essb.eur.nl Department of Public

Administration and Sociology, Erasmus University Rotterdam, Rotterdam, Netherlands

\begin{abstract}
IMISCOE, it is argued, has played a key role in institutionalising migration studies. This commentary explores the bibliometric data from the opening article of this series to examine this claim more deeply, and finds indications of an 'IMISCOE effect'. The network is increasingly prominent in the field; it has established a 'citation community' among its members; it has been a key part of the internationalisation of the field. Its influence is unlikely to decline, which is also a point of caution, namely, that the 'IMISCOE effect' does not belie the diversity of perspectives in migration research that exist within and beyond the network.
\end{abstract}

Keywords: IMISCOE, knowledge production, migration studies

\section{Introduction \& theory}

There are several research networks in migration studies spread across the globe. These either explicitly focus on migration, such as the Network for Migration Research on Africa and the Asia Pacific Migration Network, or migration comprises a large portion of its thematic concerns, such as with Metropolis. The IMISCOE research network falls into the former category. Initially founded as a Network of Excellence within the European Union's 6th Framework Programme in 2004, it is now one of the biggest networks of migration researchers in the world.

As the network reaches 15 years of existence, what role has it played in the evolution of the field in Europe in this period? Can we speak of an 'IMISCOE effect' on the structure and culture of knowledge production on migration? This short essay looks at how the network fits into the growth of the field since the turn of the century; to what extent member institutes are self-referential; and finally, the role it has played in internationalising migration studies. It provides not so much a history of IMISCOE, as Brus (2014) has done, but rather seeks to more deeply analyse some of the indications that emerge from the bibliometric metadata used in the opening article of this series (Levy et al. 2020).

(c) The Author(s). 2020 Open Access This article is licensed under a Creative Commons Attribution 4.0 International License, which permits use, sharing, adaptation, distribution and reproduction in any medium or format, as long as you give appropriate credit to the original author(s) and the source, provide a link to the Creative Commons licence, and indicate if changes were made. The images or other third party material in this article are included in the article's Creative Commons licence, unless indicated otherwise in a credit line to the material. If material is not included in the article's Creative Commons licence and your intended use is not permitted by statutory regulation or exceeds the permitted use, you will need to obtain permission directly from the copyright holder. To view a copy of this licence, visit http://creativecommons.org/licenses/by/4.0/. 
In that article, it became clear that migration studies entered a "new age" in the mid2000s. Not only was the field growing rapidly, with increased interdisciplinarity, but the tendency of scholars to collaborate internationally also became higher, particularly in Europe. Much of this internationalisation appears to be in parallel with the establishment of the IMISCOE (International Migration, Integration and Social Cohesion in Europe) network, whose programme has been "predicated on systematic cross-national comparative research, beyond 'methodological nationalism"' (Scholten et al. 2015, p. 319). Many of the expert interviewees consulted in Levy et al. (2020) and some of the commentaries in this series have regarded its establishment as a pivotal development when we speak of "institutionalisation" of the field.

This essay therefore goes deeper into the bibliometric evidence to interact with the claims, made in Pisarevskaya et al. (2019) and the opening article in this commentary series, that IMISCOE has played a key role in institutionalising migration studies.

\section{Data description \& methods}

Based on a complex query, comprised of the same journals and keywords as the opening article, of the Web of Science database, the dataset for this essay contains metadata for 11,678 items of English-language migration research authored by Europe-based researchers, published in the period 2004-2018. Of these, at least 1432 were by authors based at IMISCOE member institutes. It is likely that this latter figure is actually higher, due to occasional inconsistencies in which author-affiliation metadata is (not) recorded.

The data are organised into and analysed in three different phases, which align with IMISCOE's institutional history. Phase 1 (2004-2008) refers to IMISCOE's time as a European-funded Network of Excellence, co-ordinated by the University of Amsterdam's Institute for Migration \& Ethnic Studies (IMES), from its foundation in 2004. ${ }^{1}$ Phase 2 (2009-2013) refers to the period from 2009 until 2013 in which IMES continued the co-ordination, but then as an independent, member-funded network. Phase 3 (2014-2018) covers the period from which Erasmus University Rotterdam (EUR) took over the co-ordination.

Using VOSViewer (van Eck and Waltman 2010), this essay involves three categories of analysis. Firstly, it traces the growth of the field in Europe and IMISCOE's place in that growth. Secondly, it uses citation analysis, just like in the opening article, to measure the self-referentiality of IMISCOE research versus European migration research more widely. Thirdly, it analyses international co-authorships as an approximation of the internationalisation of the field, again, much like the opening article of this commentary series.

This leads to an important disclaimer about what this bibliometric-based approach can and cannot do. Firstly, because publications take time, and are often actually written several months before they appear in a journal, associating them with the Phases mentioned above means the chronology is not exact to the moment(s) when collaboration occurred. Secondly, because of the English-language bias of this dataset arising from Web of Science's coverage, there is an underrepresentation of the contribution of scholars who published in other languages, notably French, German, and

${ }^{1}$ The EU funding actually came to an end in 2009 but dividing the metadata according to specific dates within years was not possible. Therefore, all metadata from 2009 is included in Phase 2. Likewise, all metadata from 2014 is included in Phase 3. 
Spanish. With these considerations taken together, while this article cannot provide an exact picture of IMISCOE's place within European migration scholarship, it can, at the very least, approximate it.

\section{Growth}

As Fig. 1 shows, the IMISCOE network has grown from 19 member institutes and four affiliates $^{2}$ during phase 1 , to over 50 today (47 at the end of 2018). This has not been a constant growth; when the EU funding ended in 2009, some institutes left the network. Some of them later returned, while several new institutes have joined IMISCOE in the 2010s.

According to the dataset, over 3500 organisations (usually meaning universities) in Europe published research on migration in the period 2004-2018. Many of these organisations published only one or a handful of articles. That number decreases to 310 if only organisations with 10 or more publications in the dataset are included; and to 100 for organisations with 30 or more publications. Of these 100, 29 are or have been IMIS COE members. Several of these can be identified in Fig. 2.

In terms of publications, during Phase 1, the network accounted for around $10 \%$ of European migration publications. Given its fewer member institutes during Phase 2, it is not surprising that IMISCOE-institute-authored publications comprised a slightly lower proportion, just under 9\%, in this time. However, during Phase 3, this increased to around $15 \%$. In fact, in 2018, over $20 \%$ of Europe-based publications on migration were authored by scholars based at IMISCOE member institutes. If institutions in Europe who have only produced a small number of publications on migration are excluded from the analysis, then the proportion of publications coming from IMISCOE institutes is even higher. In terms of research output, then, IMISCOE has established an empirically growing presence in the field in terms of the volume of articles.

\section{Self-referentiality}

The same equation as in the opening chapter of this series (see Levy et al. 2020, p. 8) was used to analyse citation links between organisations, authors, and documents in the dataset. The data show that in European migration scholarship, $0,05 \%$ of the potential citation links between organisations that produced 10 or more pieces of research on migration between 2004 and 2018 have been exploited. When this analysis is limited

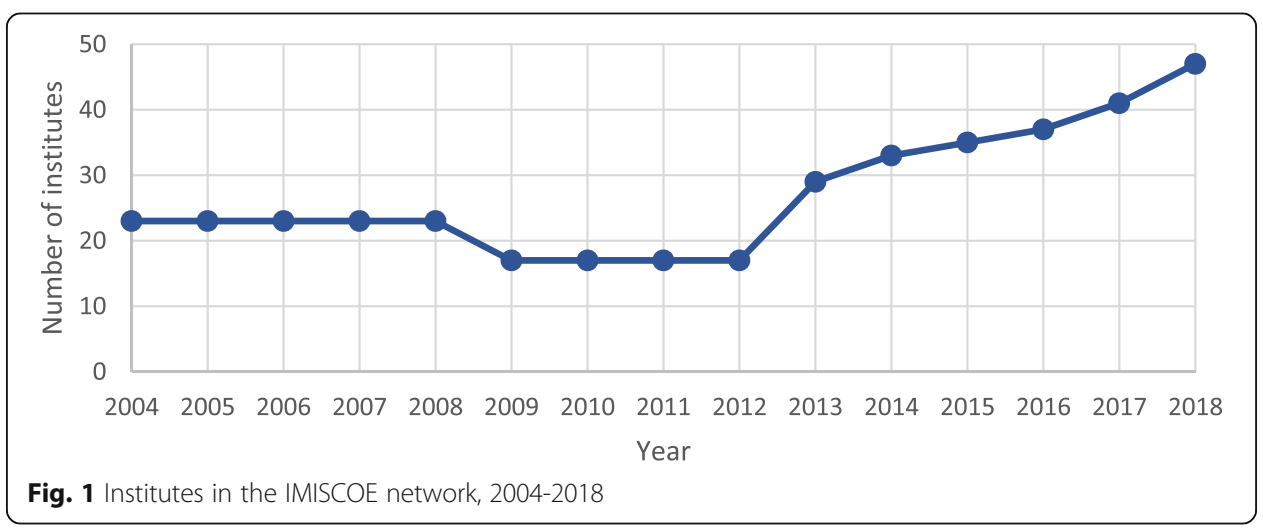




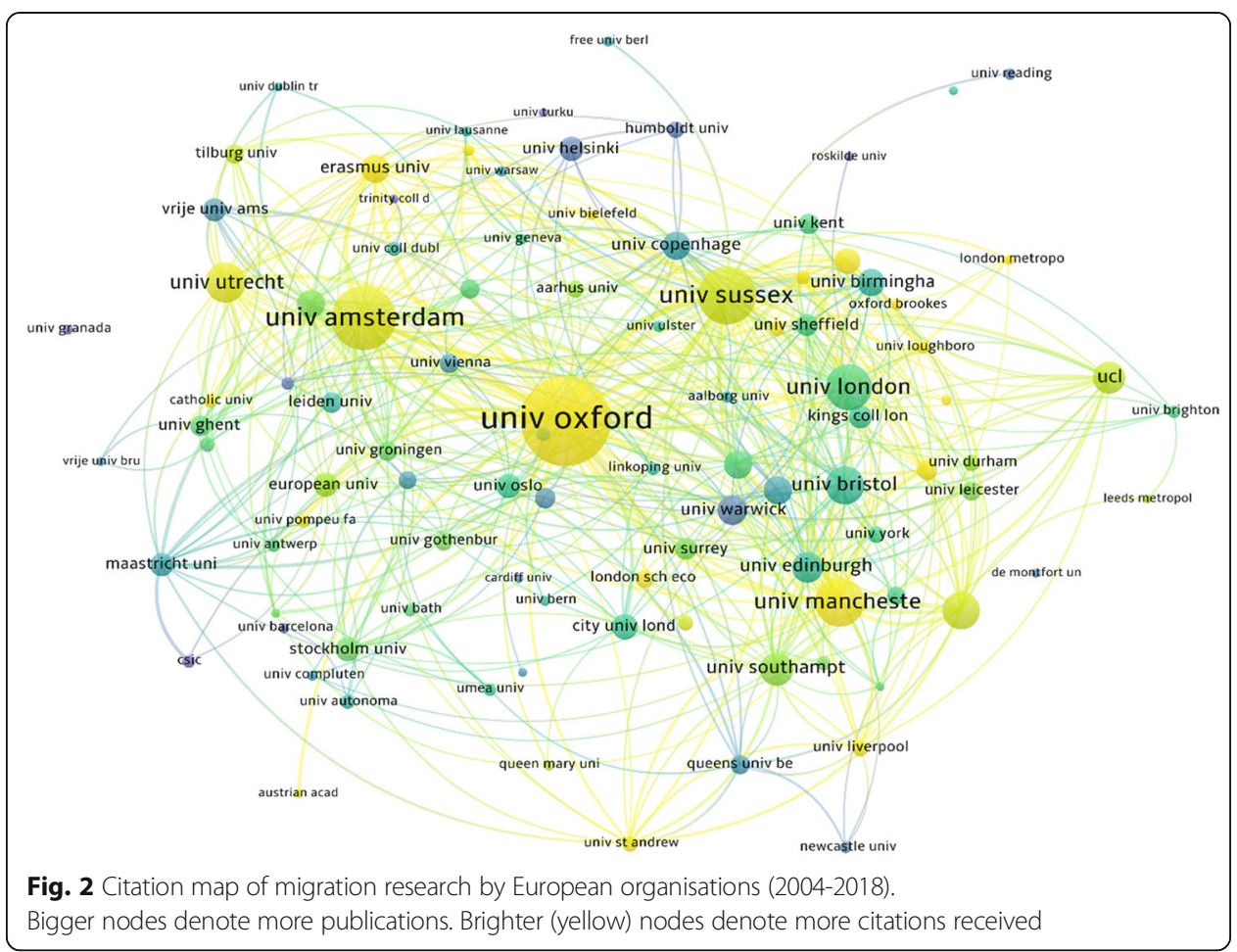

to IMISCOE member institutes only, 2,63\% of the potential citation links were exploited. Among authors with five or more publications in the dataset, 2,31\% of the potential citation links were exploited Europe-wide. For those with five or more publications in the dataset and who were based at an IMISCOE member institute (or who co-authored with somebody who was), $8,11 \%$ of the potential links were exploited. These percentages are $0,33 \%$ and $1,04 \%$ respectively for authors with two or more publications. Following the same measure for self-referentiality as we used in the opening article, among documents which received 30 or more citations, $0,2 \%$ of potential links were exploited. Among documents authored by those based at IMISCOE member institutes, the proportion was $0,7 \%$. In short, migration researchers based at IMISCOE institutes are more likely to cite each other than migration researchers in Europe more generally are to cite each other. This implies that the network has facilitated citation connections between its members, or, so to speak, a citation community.

Figure 3 illustrates the evolution of this citation community rather strikingly, by showing the density of citation links between articles authored by at least one author from an IMISCOE member institute, across the three phases. As the number of publications produced by IMISCOE members increased, a core set of papers referencing one another emerged from what was during Phase 1 a rather disparate set of publications. Prominent articles, or, in Fig. 3's visual logic, 'hotter' articles are those which have more citation links in either direction to other articles by IMISCOE authors. To give some examples that appear in this core, the five articles with the most links in either direction are Snel et al. (2006), Erdal and Oeppen (2013), Crul and Schneider (2010), King (2012), and Ryan and Mulholland (2014). Figure 3 illustrates that the number of articles in this 'hot' area have increased significantly over time, and, to stretch that metaphor slightly, that the warmth of the citation community has spread. 


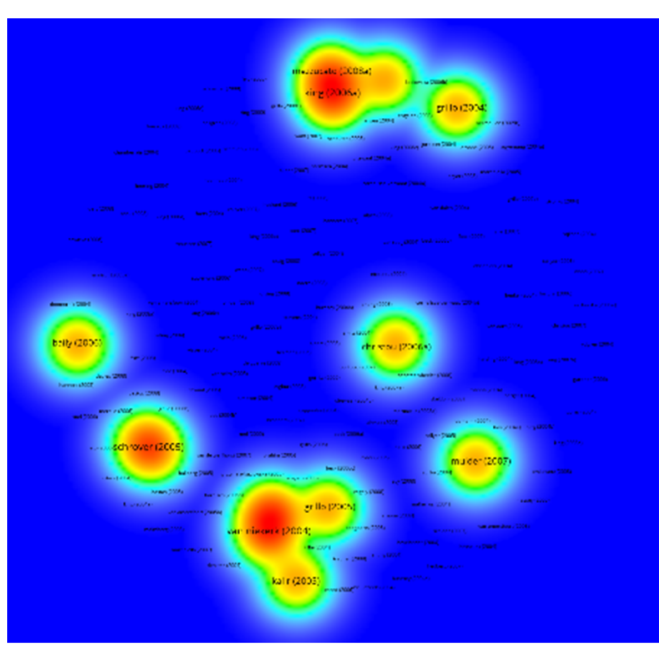

Phase 1 (2004-2008)

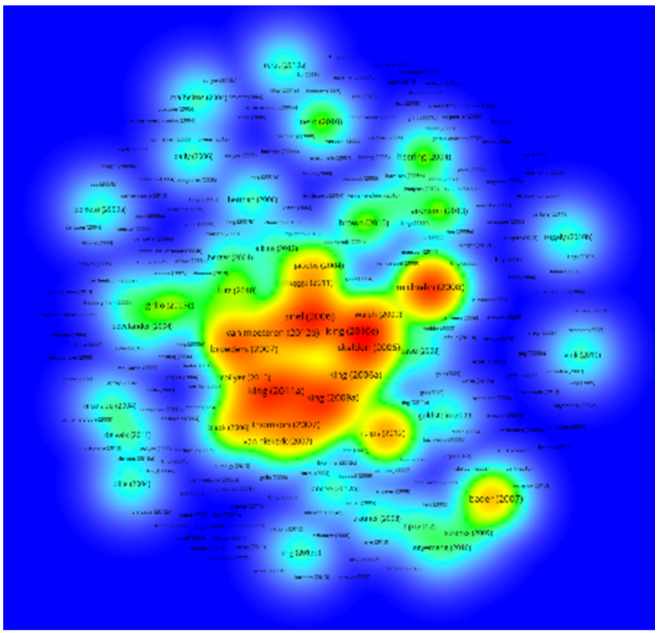

Phase 2 (2009-2013)

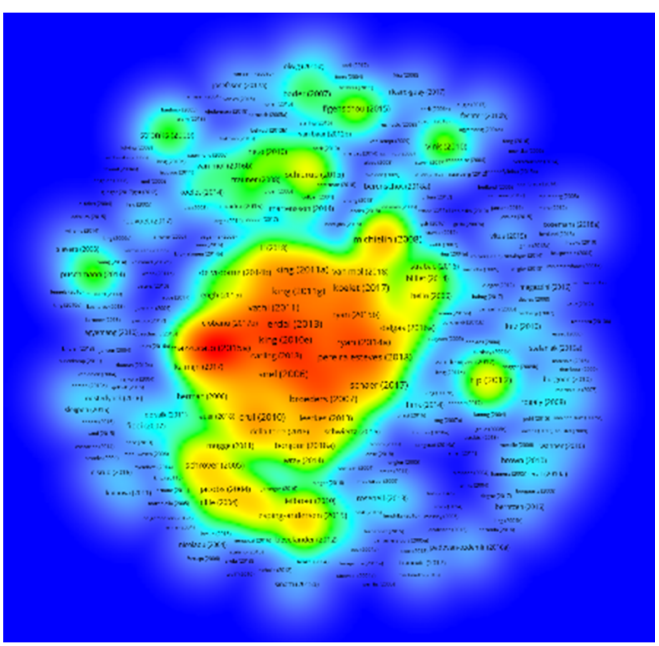

Phase 3 (2014-2018)

Fig. 3 Density of citation links between IMISCOE articles over 3 phases 
This is further illustrated in Fig. 4, which shows the increasing likelihood of IMIS COE-member-authored publications to cite one another since the network's formation in 2004. At the end of phase 1, there were 15 citation links between 220 articles. This increased to 161 links across 536 articles at the end of phase 2. By the end of phase 3, there were 796 links across 1432 articles.

Thus, over the past 15 years, IMISCOE members have been more likely to cite one another than have Europe-based migration scholars more widely. Not only this, but the likelihood of IMISCOE members to cite one another has also increased over time, with a growing body of literature forming the core of this citation community.

\section{Internationalisation}

Internationalisation is perhaps the area of institutionalisation in which the expert interviewees for the opening article argued that IMISCOE had played a key role. Indeed, the results of the data analysis showed that European researchers had a tendency to collaborate internationally, with $36 \%$ of Europe-produced migration research being internationally co-authored (Levy et al. 2020). By once again analysing international coauthorships, two questions are considered in this section: (1) To what extent has IMIS COE research involved international collaboration, compared to European migration research more widely? (2) How large a proportion of international co-authorships in Europe have involved IMISCOE members?

Regarding the first question, Table 1 shows a distinctly higher tendency among IMIS COE members to co-author internationally compared to Europe as a whole. It is true that European migration research, while of a similar volume, has been comparatively more internationally collaborative than North American migration research. However, when it comes to IMISCOE members, there is proportionally more international collaboration occurring.

As for the second question, Fig. 5 shows the number of international co-authorships per year in Europe, and the proportion of those that involved IMISCOE member institutes. IMISCOE has therefore not only been a catalyst for international collaboration among its members, but those members comprise a growing proportion of Europe's

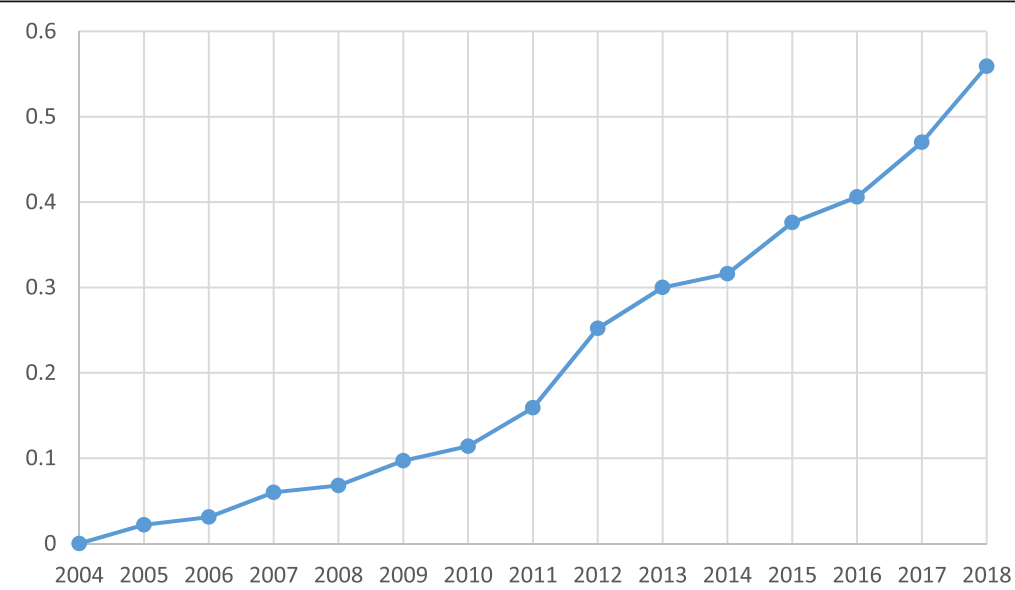

Fig. 4 Citation links between IMISCOE-member-authored articles, controlled for by numbers of articles 
total number of international co-authorship links. This is in a context of noticeably more international collaboration in the continent more widely since 2004, in which perhaps the annual IMISCOE conferences have played a role.

\section{Discussion: an IMISCOE effect on European migration studies?}

What then does this say about an "IMISCOE effect" on European migration scholarship? Bibliometrics of course cannot give a full and final answer to this question. For example, involvement with IMISCOE is certainly not limited to publications written by authors based at member institutes; the annual conference drew over 700 participants in 2018 and that number continues to grow (IMISCOE 2019a, 2019b). Moreover, as other commentaries in this series have noted, internationalisation goes far beyond measuring co-authorships (Kofman 2020; Chan 2020); communities of scholars exist without appearing on citation maps (King 2020); and the transmission of ideas is difficult to fully approximate using only bibliometric analysis (Vertovec 2020). However, such analyses can add empirics to inklings that scholars may feel about the field. In this regard, based on the observations they made, the interviewees in the opening article would as a whole probably answer the question posed in this essay in the affirmative. Since there are things that respondents know that bibliometrics cannot show, and vice versa, this is important to remember when discussing the conclusions. With that in mind, what do the bibliometric data show? While the data do not show an undeniable IMISCOE effect on migration scholarship, they do highlight its growing presence and importance in the field. I speculate that this indicates its key future role in the institutionalisation (Levy et al. 2020) of migration studies. However, this observation must be balanced with the fact that there is a significant amount of research - most European migration research - that occurs beyond IMISCOE member institutes. Thus, I here offer four points of commentary based on the analyses in this brief essay and in the opening article of this series.

Firstly, that IMISCOE members comprise over a quarter of the most prolific research institutes is evidence of its prominence in European migration scholarship over the past 15 years, but not its dominance. At the time of its formation, its 19 members represented "roughly the institutionalised research capacity in Europe at that moment" (Penninx in IMISCOE 2019a, 2019b, p. 8). However, there is a great deal of migration research occurring in Europe beyond IMISCOE, often in noninstitutionalised settings; migration research does not only happen in migration research institutes but (still) often by researchers based in and identified with mainstream disciplines.

IMISCOE therefore exists in the context of a much bigger field of migration studies, or more specifically, migration researchers. The IMISCOE articles comprise 1432 out

Table 1 Number of international co-authorships vs. number of articles published

\begin{tabular}{llcll}
\hline & $\begin{array}{l}\text { All Europe } \\
\text { Links / Articles }\end{array}$ & & \multicolumn{2}{l}{$\begin{array}{l}\text { IMISCOE } \\
\text { Links / Articles }\end{array}$} \\
\hline Phase 1 & 337 & 2150 & 48 & 220 \\
Phase 2 & 990 & 3527 & 254 & 316 \\
Phase 3 & 2174 & 6001 & 514 & 896 \\
\hline
\end{tabular}




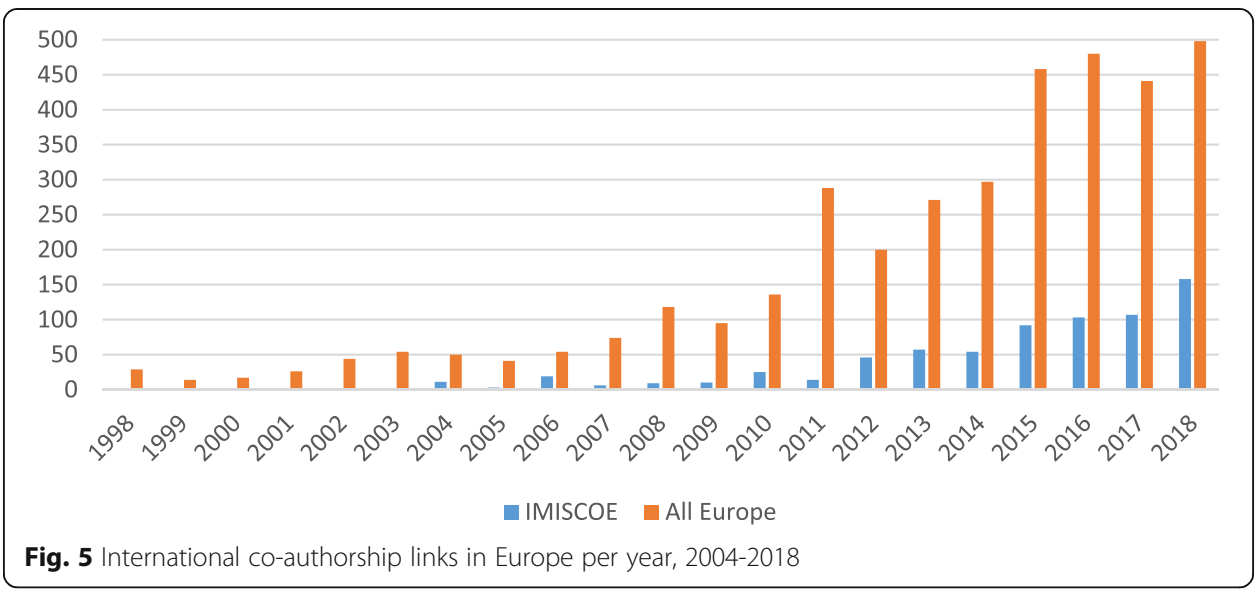

of a total of nearly 12,000 produced in Europe in the past 15 years, and although this essay possibly underestimates any effect IMISCOE might have had on the field, there have still been thousands upon thousands of publications and projects on migration beyond the network (see also Migration Research Hub 2020). In sum, while IMISCOE has been strong in bringing institutes together, there may be scope for the future integration of individuals from non-member institutes. This may also serve to bring mainstream disciplinary perspectives 'back' into migration studies, or, conversely, to mainstream the field itself.

Secondly, the growing prominence of IMISCOE - if the trajectories highlighted by the data are to continue - suggests that its influence in the field is likely to increase in coming years. This is especially true given the continuing influx of new member institutes, including from outside Europe. This brings significant opportunities to continue building a research infrastructure for the field, but also certain risks that it does not belie the diversity of perspectives in migration research that exist within and beyond the network. There is, after all, a worldview behind every institution, or, as DeWind (2020) has already reflected, the possibility that institutionalisation really means homogenisation. Homogenisation may be detrimental to scientific development and knowledge production (Kuhn 2012). Initiatives such as the recently-established standing committee for reflexive migration studies may be used as vehicles to avoid this.

Thirdly, researchers based at IMISCOE institutes are more likely to cite one another than migration researchers in Europe more generally. The data suggest that the network has become ever more close-knit in recent years. This, perhaps, reflects how IMISCOE has been exceptional, in terms of its goal of building an integrated research programme, compared to other Networks of Excellence, though a more systematic analysis would shed more light on this assertion. That a citation community, as I have called it above, has emerged, indicates the potential of formalised networks, or 'networks of excellence', such as IMISCOE to facilitate collaboration and the communication of ideas. However, returning to the homogenisation point raised above, self-referentiality ought not to become exclusivity.

Fourthly, perhaps the strongest indicator of an 'IMISCOE effect' has been in the internationalisation of European migration scholarship. The annual conference is the biggest migration-research-related event in Europe, no doubt functioning as a catalyst 
for international collaboration. Such international collaboration can be concretely observed in international co-authorships. Proportionally speaking, international coauthorships among IMISCOE members have been a distinct feature of its output over the past 15 years when compared with non-members. This speaks to broader theoretical debates on methodological nationalism (see Brus 2014). In this sense, IMISCOE has played a significant role in the internationalisation of migration studies. This is an interesting point to consider as the network considers a future more global strategy, where it can at present perhaps be critiqued for its Eurocentricity. On this note, IMIS COE may indeed have a role to play in overcoming the 'uneven', or, as Kofman (2020) puts it, 'unequal' internationalisation of migration studies, as well, of course, as institutionalisation more widely.

Acknowledgements

The author would like to thank Professor Rinus Penninx for his clarifying comments regarding the historical aspects of this article.

\section{Author's contributions}

The author(s) read and approved the final manuscript.

\section{Competing interests}

The author declares that he has no competing interests.

Received: 1 May 2020 Accepted: 1 May 2020

Published online: 02 October 2020

References

Brus, A. (2014). Excellence, diversity, and growth: a historical biography of the IMISCOE research network. Nijmegen: Radboud University Nijmegen.

Chan, Y. (2020). Asian perspectives of migration: a commentary. Comparative Migration Studies, 8. https://doi.org/10.1186/s40878020-00190-5.

Crul, M., \& Schneider, J. (2010). Comparative integration context theory: participation and belonging in new diverse European cities. Ethnic and Racial Studies, 33(7), 1249-1268.

DeWind, J. (2020). Blind men and the elephant: one view of the field of migration studies. Comparative Migration Studies, 8. https://doi.org/10.1186/s40878-020-00191-4.

Erdal, M. B., \& Oeppen, C. (2013). Migrant balancing acts: understanding the interactions between integration and transnationalism. Journal of Ethnic and Migration Studies, 39(6), 867-884

IMISCOE (2019a). 2018 annual report. Rotterdam: IMISCOE.

IMISCOE. (2019b). Research database. Retrieved January 14, 2020, from migration research hub: http://www. migrationresearch.com

King, R. (2012). Geography and migration studies: retrospect and prospect. Population, Space and Place, 18, 134-153.

King, R. (2020). On migration, geography, and epistemic communities. Comparative Migration Studies, 8. https://doi.org/10. 1186/s40878-020-00193-2.

Kofman, E. (2020). Unequal internationalisation and the emergence of a new epistemic community: gender and migration. Comparative Migration Studies, 8. https://doi.org/10.1186/s40878-020-00194-1.

Kuhn, T. S. (2012). The structure of scientific revolutions. Chicago: The University of Chicago Press.

Levy, N., Pisarevskaya, A., \& Scholten, P. (2020). Between fragmentation and institutionalization: the rise of migration studies as a research field. Comparative Migration Studies, 8, 1-24. https://doi.org/10.1186/s40878-020-00180-7.

Migration Research Hub (2020). Research Database. https://migrationresearch.com/search. Accessed Mar 2020

Pisarevskaya, A., Levy, N., Scholten, P., \& Jansen, J. (2019). Mapping migration studies: An empirical analysis of the coming of age of a research field. Migration Studies. https://doi.org/10.1093/migration/mnz031.

Ryan, L., \& Mulholland, J. (2014). Trading places: french highly skilled migrants negotiating mobility and emplacement in London. Journal of Ethnic and Migration Studies, 40(4), 584-600.

Scholten, P., Entzinger, H., \& Penninx, R. (2015). Research-policy dialogues on migrant integration in Europe: comparison and conclusions. In P. Scholten, H. Entzinger, R. Penninx, \& S. Verbeek (Eds.), Integrating immigrants in Europe: research-policy dialogues (pp. 315-336). Dordrecht: Springer.

Snel, E., Engbersen, G., \& Leerkes, A. (2006). Transnational involvement and social integration. Global Networks, 6(3), 285-308.

Van Eck, N. J., \& Waltman, L. (2010). Software survey: VOSviewer, a computer program for bibliometric mapping. Scientometrics, 84(2), 523-538.

Vertovec, S. (2020). Two cheers for migration studies. Comparative Migration Studies, 8. https://doi.org/10.1186/s40878-020-00195-0.

Publisher's Note

Springer Nature remains neutral with regard to jurisdictional claims in published maps and institutional affiliations. 